\title{
THEORY OF IRRADIATION HARDENING OF METALS AND ALLOYS BASED ON THE ENERGY CONDITION OF PLASTICITY
}

\author{
Konobeev Yu.V.* ${ }_{2}^{* *}$, Pechenkin V.A. ${ }_{2} * *$ and Garner F.A.*** \\ * JSC «SSC RF-IPPE n.a. A.I. Leypunsky», \\ 1 Bondarenko sq., Obninsk, Kaluga reg., 249033 Russia \\ * * Obninsk Institute for Nuclear Power Engineering, National Research Nuclear \\ University MEPhI, 1 Studgorodok, Obninsk, Kaluga reg., 249040 Russia \\ *** Radiation Effects Consulting, 2003 Howell Avenue, Richland WA, USA
}

A conventional approach for estimating the yield strength consists in calculation of a critical shear stress for bowing out of gliding dislocation segments between barriers. According to Orovan theory, the critical shear stress $\tau_{k}$ is determined by the average distance $l$ between obstacles: $\tau_{k}=\alpha G b / l$, where $\alpha$ is the constant; $G$ is the shear module; $b$ is the Burgers vector.The superposition of various barriers is taken into account as additive of different contributions $\tau_{k}=\tau_{1}+\tau_{2}+\tau_{3}+\ldots$, or as $\tau_{k}^{2}=\tau_{1}^{2}+\tau_{2}^{2}+\tau_{3}^{2}+\ldots$. Both procedures have yet no theoretical ground. On the basis of the maximum shear stress concept, the critical shear stress $\tau_{\text {p }}$ in polycrystals is related to the tensile yield strength $\sigma_{y}$ as follows: $\sigma_{y}=2 \tau_{k}{ }^{k}$ (Tresca criterion). On the basis of the effective stress concept this relationship has well known form: $\sigma_{y}=(\sqrt{ } 3) \tau_{k}$ (Mises criterion). Sometimes the Taylor criterion is used, according to which $\sigma_{y}=3.06 \tau_{k}$.

In the present paper an another method of calculating the yield strength of metals and alloys is proposed. The energy condition of plasticity (Mises criterion) is used. According to this condition the plastic flow of a material occurs when the deformation potential energy which is proportional to the square of the effective stress $\sigma_{\text {eff }}$, reaches a certain limiting value proportional to the square of the yield stress $\sigma$ under uniaxial tension.

In this paper, it is assumed that for the onset of plastic flow the specific potential energy of deformation caused by external forces should exceed the limiting value equal to the potential energy of deformation created by all microstructure defects (dislocations, dislocation loops, voids, precipitates, etc.). Such an approach allows to calculate barrier strengthening coefficients $\alpha$. Also, according to this approach the total yield stress is equal to the square root of the sum of yield stress squares for different types of crystal defects («geometric superposition of strengthening barriers contributions»).

Key words: irradiation hardening, yield strength, metals, alloys, dislocations, voids, precipitates.

\section{INTRODUGTION}

A common approach for the explanation of the yield strength change in irradiated materials (irradiation hardening) is based on the model of hardening by barriers for gliding

(c) Konobeev Yu.V., Pechenkin V.A., Garner F.A., 2017 
dislocations. According to such an approach the motion of dislocations under an applied shear stress $\tau_{k}$ is impeded by localized obstacles randomly distributed in the glide plane. To initiate a macroscopic plastic strain, dislocations should overcome these obstacles. This overcoming can be realized by bowing out of dislocations between the barriers (Orowan mechanism) or by cutting them. The stress $\tau_{k}$ is determined by the mean distance $l_{k}$ between two neighbor obstacles of the same type: $\tau_{k}=A_{k} / l_{k}$, where $A_{k}=\alpha_{k} G b$ for the Orowan mechanism ( $\alpha_{k}$ is the constant, $G$ is the shear modulus, and $b$ is the Burgers vector) and $A_{k}=F_{k}(T) / b l_{k}$ for the cutting mechanism [1 - 4]. The constants $\alpha_{k}$ are usually determined by fitting experimental data on the yield strength. The superposition of various barriers is taken into account as additive of different contributions $\tau_{k}=\tau_{1}+\tau_{2}+\tau_{3}+\ldots$, or as $\tau_{k}{ }^{2}=\tau_{1}{ }^{2}+\tau_{2}{ }^{2}+\tau_{3}{ }^{2}+\ldots$ [ $\left.4-6\right]$. Both procedures have yet no theoretical ground. On the basis of the maximum shear stress concept, the critical shear stress $\tau_{k}$ in polycrystals is related to the tensile yield strength $\sigma_{y}$ as follows: $\sigma_{y}=2 \tau_{k}$ (Tresca criterion). On the basis of the effective stress concept this relationship has well known form: $\sigma_{y}=3^{1 / 2} \cdot \tau_{k}$ (Mises criterion). Sometimes the Taylor criterion is used, according to which $\sigma_{y}=3.06 \cdot \tau_{k}$.

In the present work a new approach for calculating the yield strength is developed. The yield strength of a material is considered to be the square root of the squared effective stress $\sigma_{\text {eff, }}$ created by all barriers in an arbitrary point of a material. As is known, the tensile yield strength equals the effective stress. Such an approach allows to obtain explicit expressions for hardening constants. Besides, in this approach $\sigma_{y}{ }^{2}=\sigma_{y 1}{ }^{2}+\sigma_{y 2}{ }^{2}+\sigma_{y 3}{ }^{2}+\ldots$, if lattice defects of different type $i(i=1,2,3, \ldots)$ are present in the microstructure.

\section{ENERGY CONDITION OF PLASTICITY}

According to the energy condition (criterion) of plasticity proposed by Mises (see, for example, [7]), the plastic deformation occurs when the effective stress ("stress intensity") reaches some value $\sigma_{y}$, which depends only on the material properties. For isotropic materials, this energy condition consists in the requirement that the square of the effective stress is to be invariant (Mises law): $\sigma^{2}$ eff $=3 I_{2}$, where $I_{2}=s_{i j} s_{j i} / 2$ is the second invariant of the deviatoric part of the stress tensor $s_{i k}=\sigma_{i k}-\delta_{i k}\left(\sigma_{11}+\sigma_{22}+\sigma_{33}\right) / 3\left(\delta_{i k}\right.$ is the unit tensor). The effective stress square can be expressed as follows:

$$
\sigma_{\text {eff }}^{2}=\left[\left(\sigma_{11}-\sigma_{22}\right)^{2}+\left(\sigma_{22}-\sigma_{33}\right)^{2}+\left(\sigma_{33}-\sigma_{11}\right)^{2}+6\left(\sigma_{12}{ }^{2}+\sigma_{23}{ }^{2}+\sigma_{31}{ }^{2}\right)\right] / 2 .
$$

As is known, the energy condition of plasticity is derived from the following requirement: the plastic deformation occurs when the potential energy of deformation which is proportional to $\sigma^{2}$ eff reaches some limiting value, so that $\sigma^{2}$ eff $=\sigma^{2}$.

From the existing theoretical models and experiments it follows that $\sigma_{y}$ is determined by the microstructure of a material. It is natural to assume that the square of the yield stress $\sigma_{y}{ }^{2}=\sigma^{2}$ eff is determined by elastic stress fields created at an arbitrary point of the crystal by all lattice defects. As a first approximation, it will be assumed that each crystal defect creates a potential energy of deformation independently of other defects, that is, the square of the effective stress is equal to the sum of the squares of the effective stresses created by lattice defects. As shown below, such an approach allows to derive contributions of various types of crystal defects (dislocations, voids and gas bubbles, precipitate particles, etc.) to the yield strength and substantiate the method of their superposition.

As it will be shown below, well known contributions to hardening of crystal defects such as dislocations, voids, gas bubbles, dislocation loops, precipitates, etc. can be derived if to suppose that at each point of a material the square of the yield strength is determined by the expression (1) averaged over the spatial distribution of these defects, the stress tensor is determined by elastic strain fields caused by the defects. The approach consists in calculation of $\sigma^{2}$ eff at an arbitrary point of the matrix taking into account elastic stresses produced by all components of microstructure. 


\section{HARDENING BY DISLOCATIONS}

Screw dislocations. Let's consider a straight screw dislocation, which line coincides with the coordinate axis $z$. According to Ref. [8], in cylindrical coordinate system all components of the stress tensor at an arbitrary point around of the screw dislocation are equal to zero, excluding the component $\sigma_{z \varphi}$, which is equal to

$$
\sigma_{z \varphi}=G b /(2 \pi r)
$$

where $G$ is the shear modulus of the matrix, $b$ is the Burgers vector. By writing eq. (1) in the cylindrical coordinates (by replacing $1,2,3 \rightarrow z, r, \varphi$ ) and substituting eq. (2) in eg. (1), one obtains the following expression for $\sigma^{2}$ eff :

$$
\sigma^{2} \text { eff }=3 \sigma^{2} z \varphi=3(G b)^{2} /(2 \pi r)^{2} \text {. }
$$

In order to take into account the contribution of all screw dislocations, the right part of eq. (3) should be multiplied by $\rho_{s}^{\prime} 2 \pi r d r$, where $\rho_{s}^{\prime}$ is the dislocation density measured by the etching method. The value of $\rho_{s}^{\prime}$ is linearly related to total density of screw dislocations $\rho_{s}$, measured using an electronic microscope: $\rho^{\prime}{ }_{s}=\rho_{s} / a$, where $a \approx 2$. Integrating over $r$ from $r_{0}\left(r_{0}\right.$ is the radius of the dislocation core) to maximum distance $R_{s^{\prime}}$ which can be taken mean grain or crystal size, one obtains:

$$
\sigma_{s}=\alpha_{d s} G b_{s} \sqrt{\rho_{s}},
$$

where

$$
\alpha_{d s}=\left[(3 / 2 \pi a) \ln \left(R_{s} / r_{0}\right)\right]^{1 / 2}
$$

Edge dislocations. Let's take into account the contribution of straight edge dislocations to the square of effective stress using well known result of the theory of elasticity, according to which for an edge dislocation only the following stress tensor components are non-zero [3]:

$$
\sigma_{r r}=\sigma_{\varphi \varphi}=-D \sin \varphi / r, \quad \sigma_{r \varphi}=D \cos \varphi v / r,
$$

where $D=G b_{e} / 2 \pi(1-v), v$ is the Poisson ratio, $b_{e}$ is the Burgers vector of the edge dislocation.

By averaging $\sigma^{2}$ eff over angle $\varphi$ and over distance $r$ of edge dislocations from a given point, one obtains:

$$
\sigma_{e}=\alpha_{d e} G b_{e} \sqrt{\rho_{e}},
$$

where $\alpha_{d e}=\left[(4 \pi / a) \ln \left(R_{e} / r_{0}\right)\right]^{1 / 2} /[2 \pi(1-v)]$.

The coefficients $\alpha_{d s}$ and $\alpha_{d e}$ depend slightly on material parameters and dislocation densities.

It is easy to calculate the contribution of both screw and edge dislocations to $\sigma^{2}$ eff, if spatial distributions of these dislocations are random. Apparently, in this case the value of $\sigma^{2}$ eff is equal to

$$
\sigma_{d}=G \sqrt{\alpha_{d s}^{2} b_{s}^{2} \rho_{s}+\alpha_{d e}^{2} b_{e}^{2} \rho_{e}} .
$$

In the case, when $\alpha^{2}{ }_{d s} b_{s}^{2} \approx \alpha^{2}{ }_{d e} b^{2}$, the yield strength is determined in fact, by the square root of the total dislocation density $\rho_{d}=\rho_{s}+\rho_{e}$.

\section{STRENGTHENING BY VOIDS}

According to the theory of elasticity (see, for example, [9]) stresses around of a spherical cavity of radius $R$ with the internal pressure $p$, in spherical coordinates have the following form:

$$
\sigma_{y y}=-p(R / r)^{3}, \quad \sigma_{\theta \theta}=\sigma_{\varphi \varphi}=(p / 2)(R / r)^{3},
$$

where $r$ is the distance from the void center up to a given point. Non-diagonal components 
of the stress tensor are equal to zero. In the case of a gas-filled cavity, the pressure $p$ is equal to

$$
p=p_{g}-(2 \gamma / R),
$$

where $p_{g}$ is the gas pressure in the cavity, $\gamma$ is the surface energy.

Writing eq. (1) in spherical coordinates $(1,2,3 \rightarrow r, \theta, \varphi)$, one can be easily convinced that at the distance $r$ from the cavity center the square of effective stress is given by

$$
\sigma^{2} \text { eff }=(9 / 4) p^{2}(R / r)^{6} \text {. }
$$

In order to take into account the contribution of all gas-filled cavities, is necessary multiply eq. (11) by $f_{v}(R) d R 4 \pi r^{2} d r$, where $f_{v}(R)$ is the cavity size distribution function and to integrate over $r$ from $R$ to $\infty$, and then over $R$ from 0 to $\infty$. As a result one obtains that

$$
\sigma_{\text {void }}^{2}=3 \pi \int_{0}^{\infty} R^{3}\left(p_{g}-2 \gamma / R\right)^{2} f_{v}(R) d R
$$

It is seen from the expression (12), that in the case when the gas pressure in the cavities is counterbalanced by surface tension (cavities are equilibrium gas bubbles), such cavities do not contribute to the effective stress.

For voids $\left(p_{g}=0\right)$ from eq. (12) it follows that

$$
\sigma_{\text {void }}=\alpha_{v} G b \sqrt{N_{v}<d_{v}>} \text {. }
$$

where $N_{v}$ and $<d_{v}>$ are the void number density and the mean void diameter, respectively, and

$$
\alpha_{v}=(6 \pi)^{1 / 2}(\gamma / G b)=4.34(\gamma / G b) .
$$

Apparently, the surface energy $\gamma$ is the most uncertain value because even in pure metals it can strongly vary due to radiation-induced segregation of impurity atoms on the void surface, especially of interstitial impurities, such as carbon. For $\gamma$ magnitudes in the range of $1-2 \mathrm{~J} / \mathrm{m}^{2}$ and $\mathrm{Gb}$ magnitudes ranging from $20 \mathrm{~J} / \mathrm{m}^{2}\left(\mathrm{Ni}, \alpha-\mathrm{Fe}\right.$ ) to $40 \mathrm{~J} / \mathrm{m}^{2}$ (W) one finds, that magnitudes of barrier constant for voids fall in the interval from 0.11 to 0.43 . It should be pointed out that in the framework of the traditional approach, strengthening by voids is determined by the energy per unit length of dislocation and by the mean distance of $\left(N_{v}<d_{v}>\right)^{-1 / 2}$ between two neighbor voids on the dislocation line. In such an approach, eq. (14) can be derived, if to consider that the dislocation segment does not bow between two neighbor voids and that the elastic force with which these voids act on the segment, arises due to increase of the void surface after a shift of upper part of the voids (above a slip plane) with respect to their bottom part, i.e. due to origin of ledges on void surface.

\section{HARDENING BY PRECIPITATES}

According to Ref. [10] in an infinite isotropic matrix containing an isotropic misfitting spherical sphere (the elastic model of a precipitate) the displacements are radial, i.e. the displacement vector $\mathbf{u}$ has the form $\mathbf{u}=u_{r} \mathbf{r} / r$, where $r$ is the distance from precipitate center and

$$
\begin{array}{ll}
u_{r}=\varepsilon r_{p}^{3} / r^{2}, & r \geq r_{p \prime} \\
u_{r}=\varepsilon r, & r \leq r_{p},
\end{array}
$$

where $r_{p}$ is the radius of the precipitate, $\varepsilon$ is a parameter describing the strength of the elastic strain field. For a coherent precipitate $\varepsilon$ is related to $\delta=\Delta V /(3 V)$, the misfit between the unstrained lattices of precipitate and matrix $(\Delta V / V$ is the fractional difference in atomic volume between precipitate and matrix material) [5] by

$$
\varepsilon=G_{p}\left(1+v_{p}\right) \delta /\left[G_{p}\left(1+v_{p}\right)+2 G\left(1-2 v_{p}\right)\right]
$$


where $G_{p}, n_{p}$ are the shear modulus and Poisson ratio of precipitate material, $G$ is the shear modulus of the matrix. If $G_{p}=G$ and $v_{p}=1 / 3, \varepsilon=(2 / 3) \delta$. For elastic moduli usually found $0.5 \delta \leq \varepsilon \leq \delta[5]$.

From eq. (15) it follows, that the strain tensor components are equal to

$$
\begin{aligned}
\varepsilon_{r r} & = \begin{cases}-2 \varepsilon r_{p}^{3} / r^{3}, & r \geq r_{p} ; \\
\varepsilon_{r} & r \leq r_{p} ;\end{cases} \\
\varepsilon_{\theta \theta}=\varepsilon_{\varphi \varphi}=\frac{u_{r}}{r} & = \begin{cases}\varepsilon r_{p}^{3} / r^{3}, & r \geq r_{p} ; \\
\varepsilon_{r} & r \leq r_{p} ;\end{cases} \\
\varepsilon_{r \theta} & =\varepsilon_{r \varphi}=\varepsilon_{\theta \varphi}=0 .
\end{aligned}
$$

The components of the stress tensor are linearly related to the strain tensor components. Using the well known relations, one obtains that $\sigma_{r \theta}=\sigma_{r \varphi}=\sigma_{\theta \varphi}=0$ and

$$
\begin{gathered}
\sigma_{r r}=2 G\left[(1-v) \varepsilon_{r r}+2 v \varepsilon_{\theta \theta}\right] /(1-2 v), \\
\sigma_{\theta \theta}=\sigma_{\varphi \varphi}=2 G\left[(1-v) \varepsilon_{\theta \theta}+v\left(\varepsilon_{r r}+\varepsilon_{\theta \theta}\right)\right] /(1-2 v),
\end{gathered}
$$

where $v$ is the Poisson ratio of matrix.

The substitution of eq. (17) into (18a) and (18b) results in

$$
\begin{gathered}
\sigma_{r r}= \begin{cases}-4 G \varepsilon r_{p}^{3} / r^{3}, & r \geq r_{p} ; \\
2 G \varepsilon(1+v) /(1-2 v), & r \leq r_{p} ;\end{cases} \\
\sigma_{\theta \theta}=\sigma_{\varphi \varphi}= \begin{cases}2 G \varepsilon r_{p}^{3} / r^{3}, & r \geq r_{p} ; \\
2 G \varepsilon(1+v) /(1-2 v), & r \leq r_{p} .\end{cases}
\end{gathered}
$$

Within coherent precipitate the effective stress is equal to zero. In matrix around the precipitate the square of effective stress is given by

$$
\sigma^{2} \text { eff }=\left(\sigma_{r r}-\sigma_{\theta \theta}\right)^{2}=36 G^{2} \varepsilon^{2} r_{p}^{6} / r^{6} .
$$

To obtain the square of effective stress produced in an arbitrary point of a material by all precipitates having the radius $r_{p}$, let us assume that the spatial distribution of the precipitates is uniform. Multiplying the right-hand side of eq. (20) by $f_{p}\left(r_{p}\right) d r_{p} \times 4 \pi N_{p} r^{2} d r_{\text {, }}$ $\left(f_{p}\left(r_{p}\right)\right.$ is the distribution of precipitates on radii) and integrating over $r$ from $r_{p}$ to infinity, one obtains

$$
\sigma_{p}^{2}=36 G^{2} \varepsilon^{2}\left(\frac{4 \pi}{3} r_{p}^{3} f\left(r_{p}\right) d r_{p}\right)
$$

Further, integrating the right hand side of eq. (21) over $r_{p}$ from zero to infinity and taking square root of the result, one finally obtains

where

$$
\sigma_{p}=6|\varepsilon| G \sqrt{V_{p}},
$$

$$
V_{p}=\frac{4 \pi}{3} N_{p}\left\langle r_{p}^{3}\right\rangle
$$

is the volume fraction of coherent precipitates, $N_{p}$ is the precipitate concentration, brackets denote the mean value.

In Ref. [11] it was found, that precipitate-induced strengthening and hardening of a series of model steels and commercial reactor pressure vessel steels vary according to the square root of the volume fraction of precipitate. As it was pointed out in Ref. [11] current models [12 - 14] of the hardening produced by irradiation-induced copper-rich precipitates include such a dependence.

By assumption, stresses around of a spherical incoherent precipitate are determined by the interfacial surface energy $\gamma_{m p}$. In this case inside and outside of the precipitate only 
diagonal components of stress tensor are non-zero. Moreover, inside of the particle the diagonal components equal each to other and,. consequently, the effective stress vanishes. Outside of the particle the stress field is similar to the field around of a void. Thus, the mean effective stress in an arbitrary point can be described with expressions similar to eqs. (13), (14) (Orowan formula), if to replace $N_{v} \rightarrow N_{p}<d_{v}>\rightarrow<d_{p}>\left(d_{p}=2 r_{p}\right)$ and $\gamma \rightarrow \gamma_{m p}$ :

$$
\sigma_{p}=(32 \pi / 3)^{1 / 2}\left(\gamma_{m p} / G b\right) \cdot G b \sqrt{N_{p}<d_{p}>} .
$$

\section{STRENGTHENING BY DISLOCATION LOOPS}

According to Refs. $[15,16]$ in a cylindrical coordinate system $r, z, \varphi$ the displacements around of a circular interstitial loop of radius $R$ and with the Burgers vector $\mathbf{b}$, directed along $z$-axis, in an infinite and elasticity isotropic medium are:

$$
\begin{aligned}
& u_{r}=-[b / 4(1-v)]\left[(1-2 v) I_{1}{ }^{(0)}(\rho \zeta)-\zeta I_{1}{ }^{(1)}(\rho \zeta)\right], \\
& u_{z}=-[b / 4(1-v)]\left[2(1-v) I_{0}(0)(\rho \zeta)+\zeta I_{0}(1)(\rho \zeta)\right], \\
& u_{\varphi}=0
\end{aligned}
$$

where $\rho=r / R, \zeta=z / R(z>0)$.

$$
I_{n}^{(m)}(\rho \zeta)=\int_{0}^{\infty} t^{m} J_{n}(t \rho) J_{1}(t) \exp (-t \zeta) d t,
$$

$J_{n}$ is the $n^{\text {th }}$-order Bessel function of the first kind.

Determining with the help of eqs. (25a) - (25c) the components of strain tensor and using the well known relationship between components of stress and strain tensors, one obtains, that

$$
\begin{aligned}
& \sigma_{r r}=A\left[-I_{0}^{(1)}+(1-2 v) I_{1}(0) / \rho+\zeta I_{0}^{(2)}-\zeta I_{1}(1) / \rho\right], \\
& \sigma_{z z}=A\left[-I_{0}^{(1)}-\zeta I_{0}^{(2)}\right], \\
& \sigma_{\varphi \varphi}=A\left[-(1-2 v) I_{1}(0) / \rho+\zeta I_{1}(1) / \rho-2 v I_{0}(1)\right], \\
& \sigma_{r z}=-A I_{1}{ }^{(2)}, \quad \sigma_{r \varphi}=\sigma_{z \varphi}=0,
\end{aligned}
$$

where

$$
A=G b /[2 R(1-v)] \text {. }
$$

The expressions (27a) - (27d) allow to calculate the square of effective stress $\sigma_{\text {eff, caused }}$ by the loop of radius $R$ at an arbitrary point of matrix. Introducing the loop size distribution $f_{l}(R)$, so, that $f_{l}(R) d R$ is the concentration of loops having radius $R$, one obtains the square of the effective stress produced by all loops:

$$
\begin{aligned}
\sigma_{\text {loop }}^{2} & =4 \pi \int_{0}^{\infty} R^{3} A^{2} f(R) d R \int_{0}^{\infty} \rho d \rho \int_{0}^{\infty} d \zeta\left(\sigma_{\text {eff }} / A\right)^{2}= \\
& =\frac{\pi G^{2} b^{2}}{2(1-v)^{2}} \int_{0}^{\infty} 2 R f(R) d R \int_{0}^{\infty} \rho d \rho \int_{-\infty}^{\infty} d \zeta\left(\sigma_{\text {eff }} / A\right)^{2} .
\end{aligned}
$$

Due to a complexity of the function $\left(\sigma_{\text {eff }} / A\right)^{2}$, no attempts were undertaken to calculate integrals on $\rho$ and $\zeta$ in eq. (29). However it is clear, that the main contribution to these integrals will origin from zones adjacent to the dislocation loop core, because at large distances $r=R\left(\rho^{2}+\zeta^{2}\right)^{1 / 2}$ from the loop the function $\sigma_{\text {eff }} / A$ behaves as $1 / r^{3}$ [10], and, hence, large distances bring a small contribution. In immediate loop proximity the effective stress differs only slightly from the effective stress of a straight edge dislocation, and the integrals on $\rho$ and $\zeta$ diverge logarithmically. Taking the minimum distance from loop edge 
equal to the dislocation core radius $r_{0}$, and the maximum distance equal to the loop radius, one finds that the integral on $\rho$ and $\zeta$ will be proportional to $\ln \left(R / r_{0}\right)$. Since the logarithm is the slight function of argument, when integrating on $R$ it can be taken approximately as $\ln \left(<R_{\text {loop }}>/ r_{0}\right)$, where $<R_{\text {loop }}>$ is the mean loop radius, and without a large error can be taken out of the integral. Seemingly, the final result of calculations will be similar to eq. (6), where the following replacements is made $\left(\rho_{e} / a\right) \rightarrow 2 \pi<R_{\text {loop }}>N_{\text {loop }}$ and $\ln \left(R_{e} / r_{0}\right) \rightarrow \ln \left(<R_{\text {loop }}>/ r_{0}\right)$. In these approximations from eq. (29) it follows that

$$
\sigma_{\text {loop }}=\alpha_{\text {loop }} G b \sqrt{\left\langle d_{\text {loop }}\right\rangle N_{\text {loop }}},
$$

where $N_{\text {loop }}$ is the loop concentration, the constant $\alpha_{\text {loop }}$ is close to $\alpha_{\text {disl }}$ in magnitude.

\section{SUPERPOSITION OF VARIOUS LATTICE DEFECTS IN HARDENING}

According to the approach proposed in this paper, if there are barriers of different types in the material, the square of the effective stress will be equal to the sum of the squares of effective stresses created by the various barriers, so that

$$
\sigma_{y}=\sqrt{\sigma_{\text {disl }}{ }^{2}+{\sigma_{\text {void }}}^{2}+\sigma_{p}{ }^{2}+\ldots .} .
$$

In Ref. [16] it was shown, that Eq. (31) fits better experimental data on hardening of niobium at low neutron irradiation doses as compared with the arithmetical sum of different hardening increments. According to Ref. [17] fitting the temperature dependence of hardening in molybdenum, niobium and their dilute alloys irradiated with fast neutron fluences close to $10^{22} \mathrm{n} / \mathrm{cm}^{2}$, is considerably improved if to use eq. (31) instead of $\sigma_{y}=\sigma_{\text {disl }}+\sigma_{\text {void }}+\sigma_{\text {loop }}+\ldots$.

\section{CONCLUSIONS}

A hypothesis, according to which the yield strength is determined by the square of effective stress at an arbitrary point of a material created by all components of the microstructure (by dislocations, voids, precipitate particles, dislocation loops etc.), allows to derive analytically the hardening constants.

In the approach developed above the yield strength is equal to the root square of the total squares of effective stress caused by different hardening mechanisms in the case, if the spatial distributions of these barriers are random and independent.

\section{References}

1. Orowan E., in: Internal Stresses in Metals and Alloys. Institute of Metals, London, 1948, p. 451.

2. Diehl J. and Seidel G.P. Proc. Symp. on Radiation Damage in Reactor Materials, IAEA, Vienna, 1969, v. 1, p.187.

3. Bement A.L. Jr. in: Strength of Metals and Alloys. Proceedings of Second International Conference, ASM International. Metals Park, 0H, 1973, p. 693.

4. Was G.S. Fundamentals of Radiation Materials Science: Metals and Alloys, Springer-Verlag, New York, 2007,827 p.

5. Garner F.A., Hamilton M.L., Panayotou N.F., Johnson G.D. The microstructural origins of yield strength changes in AISI 316 during fission or fusion irradiation.J. Nucl. Mater. 1981,v. 103-104, pp. 803-808.

6. Kuleshova E.A., Gurovich B.A., Shtrombakh Ya.I., Nikolaev Yu.A., Pechenkin V.A. Microstructural behavior of VVER-440 reactor pressure vessel steels under irradiation to neutron fluences beyond the design operation period.J. Nucl. Mater.,2005, v. 342, pp. 77-89.

7. Hill R. The Mathematical Theory of Plasticity, Oxford, Clarendon Press, 1950.

8. FriedelJ. Dislocations. Pergamon Press, 1964. 
9. Landau L.D. and Lifshitz E.M. Theory of Elasticity. Moscow. Nauka Publ.,1965 (in Russian). 10. Ashby M.F. and Brown L.M. Diffraction Contrast from Spherically Symmetrical Coherency Strains. Phil.Mag. 1963, v. 8, no. 91, p. 1083.

11. Buswell J.T., Phythian W.J., McElroy R.J., Dumbill S., Ray P.H.N., Mace J. and Sinclair R.N. Irradiation-induced microstructural changes, and hardening mechanisms, in model PWR reactor pressure vessel steels.J. Nucl. Mater.1995,v. 225, p. 196.

12. Odette G.R. and Lucas G.E. Radiation Embrittlement of Nuclear Reactor Pressure Vessel Steels: An International Review, ASTM STP 909, Volume 2. The American Society for Testing and Materials, 1986, p. 206.

13. Fisher S.B. and Buswell J.T. A Model For PWR Pressure-Vessel Embrittlement. Int. J. Press. Vessel \& Piping. 1987, v. 27, no. 2, pp. 91-135.

14. Williams T.J., Burch P.R., English C.A. and Ray P.H.N. Proc. $3^{\text {rd }}$ Int. Symp. on Environmental Degradation of Materials in Nuclear Power Systems - Water Reactors, Traverse City, MI,USA (The Metallurgical Society), 1988, p. 121.

15. Keating D.T. and Goland A.N. Atomic Displacements around Dislocation Loops. J. Appl. Physics, 1968, v. 39, no. 13, p. 6018.

16. Tucker R.P., Ohr S.M. and Wechsler M.S. Proc. Symp. on Radiation Damage in Reactor Materials, IAEA, Vienna, 1969, v. 1, p. 215.

17. Moteff J., Michel D.J. and Sikka M.L. in: Defects and Defects Clusters in BCC Metals and Their Alloys. Ed. by Arsenault R.J.Nuclear Metallurgy, 1973, v. 18, p. 198.

Received 30.06.2017

\title{
Authors
}

Konobeev Yury Vasilyevich, Advisor to General Director JSC «SSC RF-IPPE», Professor

E-mail: konobeev@ippe.ru

Pechenkin Valery Aleksandrovich, Head of Laboratory JSC «SSC RF-IPPE», Associated

Professor

E-mail:vap@ippe.ru

Garner Francis Albert, President of «Radiation Effects Consulting», Richland, WA, USA

E-mail: frank.a.garner@gmail.com

удК $539.214+621.039 .531$

\section{ТЕОРИЯ РАДИАЦИОННОГО УПРОЧНЕНИЯ МЕТАЛЛОВ И СПЛАВОВ НА ОСНОВЕ ЭНЕРГЕТИЧЕСКОГО УСЛОВИЯ ПЛАСТИЧНОСТИ}

\author{
Ю.В. Конобеев ${ }_{2}^{* *}$, В.А. Печенкин ${ }^{*_{2}^{* *}}$, Ф.А. Гарнер ${ }^{* * *}$ \\ ${ }^{*}$ АО «ГНЦ РФ-ФЭИ им. А.И. Лейпунского» \\ 249033 Калужская обл., г. Обнинск, пл. Бондаренко, 1 \\ **0бнинский институт атомной энергетики НИЯУ МИФИ \\ 249040, Калужская обл., г. Обнинск, Студгородок, 1 \\ *** Radiation Effects Consulting \\ 2003 Howell Avenue, Richland WA, USA
}

\section{РЕФЕРАТ}

Общепринятый подход при оценке упрочнения состоит в вычислении критического скалывающего напряжения при продавливании сегмента скользящей дислокации между двумя однотипными барьерами. Согласно теории Орована, критическое 
сдвиговое напряжение $\tau_{k}$ определяется средним расстоянием / между препятствиями: $\tau_{k}=\alpha G b / l(\alpha-$ константа; $G$ - модуль сдвига; $b$ - вектор Бюргерса). Суперпозиция различных барьеров учитывается либо простым суммированием их вкладов $\tau_{i}(i=1,2,3, \ldots)$ в критическое скалывающее напряжение $\tau_{k}=\tau_{1}+\tau_{2}+\tau_{3}+\ldots$ либо как $\tau_{k}{ }^{2}=\tau_{1}{ }^{2}+\tau_{2}{ }^{2}+\tau_{3}{ }^{2}+\ldots$. Оба способа суммирования вкладов не имеют до сих пор теоретического обоснования. На основе принципа максимального сдвигового напряжения (критерий Треска) $\tau_{k}$ для поликристаллических образцов связывается с пределом текучести в испытаниях на растяжение $\sigma_{y}$ соотношением $\sigma_{y}=2 \tau_{k}$. На основе понятия эффективного напряжения (энергетическое условие пластичности) эта связь имеет вид $\sigma_{y}=(\sqrt{ } 3) \tau_{y}$ (критерий Мизеса). Иногда используется критерий Тейлора, согласно которому $\sigma_{y}=3.06 \cdot \tau_{k}$.

Предлагается другой способ вычисления предела текучести металлов и сплавов. Использовано энергетическое условие пластичности (критерий Мизеса), согласно которому пластическое течение материала происходит тогда, когда удельная потенциальная энергия формоизменения, пропорциональная квадрату эффек-

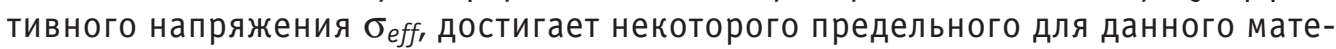
риала значения, пропорционального квадрату предела текучести $\sigma_{y}$ при одноосном растяжении.

Предполагается, что для начала пластического течения обусловленная внешними силами удельная потенциальная энергия формоизменения должна превысить предельное значение, равное удельной потенциальной энергии формоизменения, созданной всеми дефектами микроструктуры (дислокациями, дислокационными петлями, порами, выделениями и др.). Такой подход позволяет вычислить коэффициенты барьерного упрочнения $\alpha$. Согласно предлагаемому подходу, предел текучести равен корню квадратному из суммы квадратов вкладов всех типов дефектов («геометрическое» суммирование вкладов).

Ключевые слова: радиационное упрочнение, предел текучести, металлы и сплавы, дислокации, поры, частицы фазовых выделений.

\section{ЛИТЕРАТУРА}

1.Orowan E. in: Internal Stresses in Metals and Alloys. - Institute of Metals, London, 1948. $451 \mathrm{p}$.

2. Diehl J. and Seidel G.P. Proc. Symp. on Radiation Damage in Reactor Materials. - IAEA, Vienna, 1969. - Vol. 1. - P.187.

3. Bement A.L. Jr. in: Strength of Metals and Alloys. / Proceedings of Second International Conference, ASM International. - Metals Park, 0H, 1973. - P. 693.

4. Was G.S. Fundamentals of Radiation Materials Science: Metals and Alloys. - SpringerVerlag, New York, 2007. - $827 \mathrm{p}$.

5. Garner F.A., Hamilton M.L., Panayotou N.F., Johnson G.D. The microstructural origins of yield strength changes in AISI 316 during fission or fusion irradiation. // J. Nucl. Mater. 1981. - Vol. 103-104. - PP. 803-808.

6. Kuleshova E.A., Gurovich B.A., Shtrombakh Ya.I., Nikolaev Yu.A., Pechenkin V.A. Microstructural behavior of VVER-440 reactor pressure vessel steels under irradiation to neutron fluences beyond the design operation period.//J. Nucl. Mater. - 2005. - Vol. 342. PP. 77-89.

7. Hill R. The Mathematical Theory of Plasticity. - 0xford, Clarendon Press, 1950.

8. Friedel J. Dislocations. Pergamon Press, 1964.

9. ЛандауЛ.Д., Лифшиц Е.М. Теория упругости. М.: Наука, 1965.

10. Ashby M.F. and Brown L.M. Diffraction Contrast from Spherically Symmetrical Coherency Strains.//Phil. Mag. - 1963. - Vol. 8. No. 91.- P. 1083.

11.Buswell J.T., Phythian W.J., McElroy R.J., Dumbill S., RayP.H.N., Mace J. and Sinclair R.N. 
Irradiation-induced microstructural changes, and hardening mechanisms, in model PWR reactor pressure vessel steels.//J. Nucl. Mater. -1995. -Vol.225. - P. 196.

12. Odette G.R. and Lucas G.E. Radiation Embrittlement of Nuclear Reactor Pressure Vessel Steels: An International Review, ASTM STP 909, Volume 2. - The American Society for Testing and Materials, 1986. - P. 206.

13. Fisher S.B. and Buswell J.T. A Model For PWR Pressure-Vessel Embrittlement // Int. J. Press. Vessel \& Piping. - 1987. - Vol. 27. - No. 2. - PP.91-135.

14. Williams T.J., Burch P.R., English C.A. and Ray P.H.N. Proc. $3^{\text {rd }}$ Int. Symp. on Environmental Degradation of Materials in Nuclear Power Systems - Water Reactors. Traverse City, MI,USA (The Metallurgical Society), 1988. - P. 121.

15. Keating D.T. and Goland A.N. Atomic Displacements around Dislocation Loops. // J. Appl. Physics. -1968. -Vol. 39. - No.13.-P. 6018.

16. Tucker R.P., Ohr S.M. and Wechsler M.S. Proc. Symp. on Radiation Damage in Reactor Materials. -IAEA, Vienna, 1969. - Vol.1.-P. 215.

17. Moteff J., Michel D.J. and Sikka M.L. in: Defects and Defects Clusters in BCC Metals and Their Alloys. Arsenault R.J.Ed.// Nuclear Metallurgy. -1973. - Vol.18. - P. 198.

\section{Авторы}

Конобеев Юрий Васильевич, советник генерального директора по материаловедению, профессор

E-mail:konobeev@ippe.ru

Печенкин Валерий Александрович, начальник лаборатории, доцент

E-mail:vap@ippe.ru

Гарнер Френсис Альберт, президент фирмы «Radiation Effects Consulting»

E-mail: frank.a.garner@gmail.com 